\title{
Joint devices for modular removable road pavement slabs made of polymer materials for agribusiness
}

\author{
Sergey Ukolov ${ }^{1, *}$, Sergey Shevchenko ${ }^{1}$, Dmitry Simonov $^{1}$, Vladimir Trepalin ${ }^{1}$, and Liliya \\ Yustikova $^{2}$ \\ ${ }^{1}$ Peter the Great Saint Petersburg Polytechnic University, 29, Polytechnicheskaya, 195251, Saint \\ Petersburg, Russia \\ ${ }^{2}$ Saint Petersburg State University of Architecture and Civil Engineering, 4, 2nd Krasnoarmeyskaya \\ str., 190005, Saint Petersburg, Russia
}

\begin{abstract}
The article deals with the design of joint devices for a modular removable road pavement plate (slab) made of polymer materials for use in agriculture. The design of joint devices allows the use of road slabs in heavy traffic under adverse soil and hydrological conditions, with repeated assembly and disassembly. The proposed designs are simple to manufacture and ensure installation and removal of road slabs made of polymer materials within a short time.
\end{abstract}

\section{Introduction}

Joint devices for modular removable road pavement slabs [1,2] provide interconnection between pavement plates, support and transmission of load, and bending moment. In joint devices of various designs, connection of slabs is provided through the use of rigid, semirigid, or hinge locks. Each of these connection methods has its unique advantages and disadvantages.

Thus, a semi-rigid joint provides better conditions for the coating operation, but requires a more detailed planning of the base and greater strength of the connecting elements, which ensure transfer of normal and shear forces, as well as bending moments. Hinge joints are easier and more convenient for installation and removal. However, on weak bases, subsidence of the coating at joints during movement of vehicles is great [3-5]. Rigid joints ensure transmitting of normal and shear forces, as well as bending moments, but require highstrength materials and complicate assembly of the coating.

The main disadvantages of the existing designs of joint devices should include:

1. Low reliability, as the prototype joint is rigid and may get broken under temperature fluctuations, and mechanical stresses.

2. During long-term operation, the fork of the joint device may be deformed, which does not allow quick dismantling of the joint.

3. The lack of work efficiency during installation and removal.

\footnotetext{
* Corresponding author: serj.ukolov2011@yandex.ru
} 
4. Low technological effectiveness of assembly and disassembly due to a large number of small parts, difficulty of matching fork holes to the dowel bar, difficulty of disconnecting after use.

Based on the analysis of design experience [3,4,6] and use of modular removable pavements, and taking into account their installation conditions and methods, it is advisable to install such joint devices on the plates that would allow both semi-rigid and hinge connection in the longitudinal direction.

\section{Materials and Methods}

Owing to the difficulty of ensuring a good layout of the base, the articulated kind [5] of slab connection in the transverse direction when installing solid-type carriageways should only be provided. The features described above require at least two connection points near the slab corners in both longitudinal and transverse directions (Fig. 1).

As a matter of principle, the use of a large number of connection points is inappropriate, firstly, due to the added complexity of linking plates to each other; secondly, because of the complexity of technological process for manufacturing slabs with a large number of joint elements; thirdly, owing to the increased cost of both the slab manufacturing process and materials necessary for slab production.

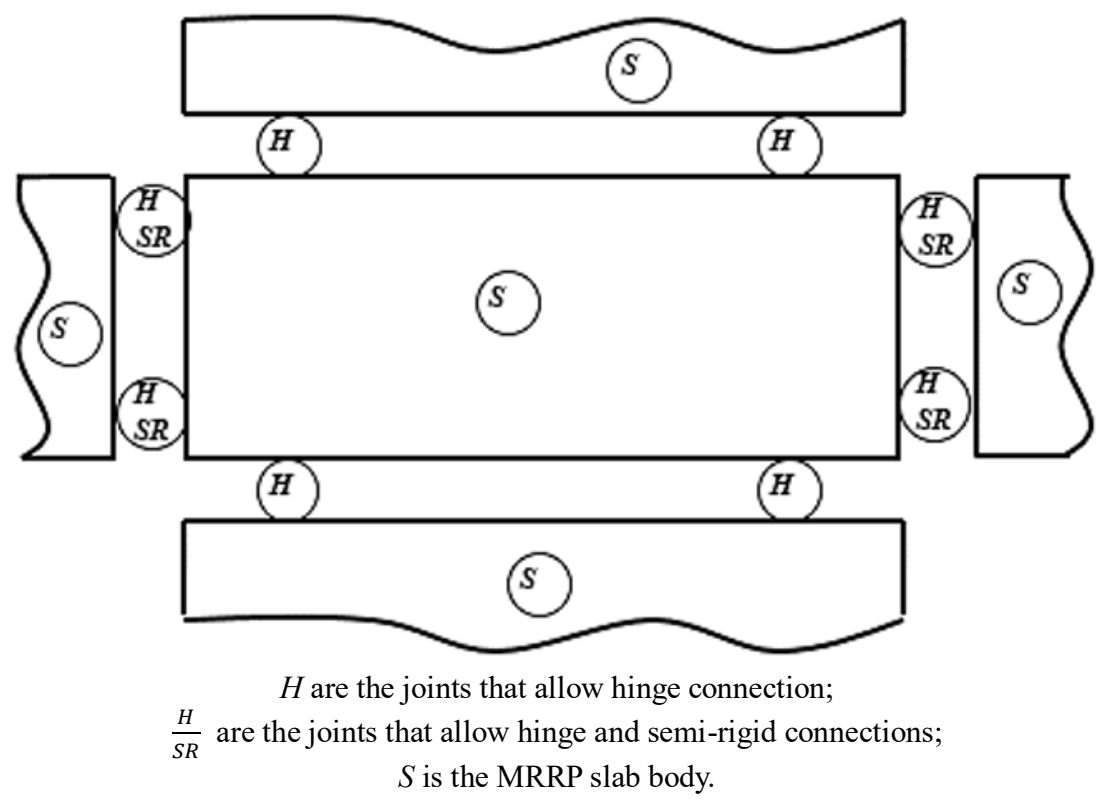

Fig. 1. Layout of connecting elements (joint locks).

Therefore, two types of joint elements are required: type A and type B. Design of these elements is shown in Fig. 2.

Be aware that the design of joint elements must ensure connection of two plates on each adjacent side of the plate perimeter (Fig. 1). Accordingly, on opposite sides of the slab, it is necessary to have connecting elements of different designs (on the "female-male" principle) (Fig. 2).

To justify the calculation methodology for the design of slab joint devices, the selection of material for the joint element and method of its attachment to the slab body are essential. Joint elements must be made of St.3-steel to ensure their required strength. The use of other 
materials (steel with high anti-wear and strength characteristics, polymeric materials, etc.) results in a steep rise in the cost of the joint device design, or insufficient strength and antiwear characteristics during repeated loading.

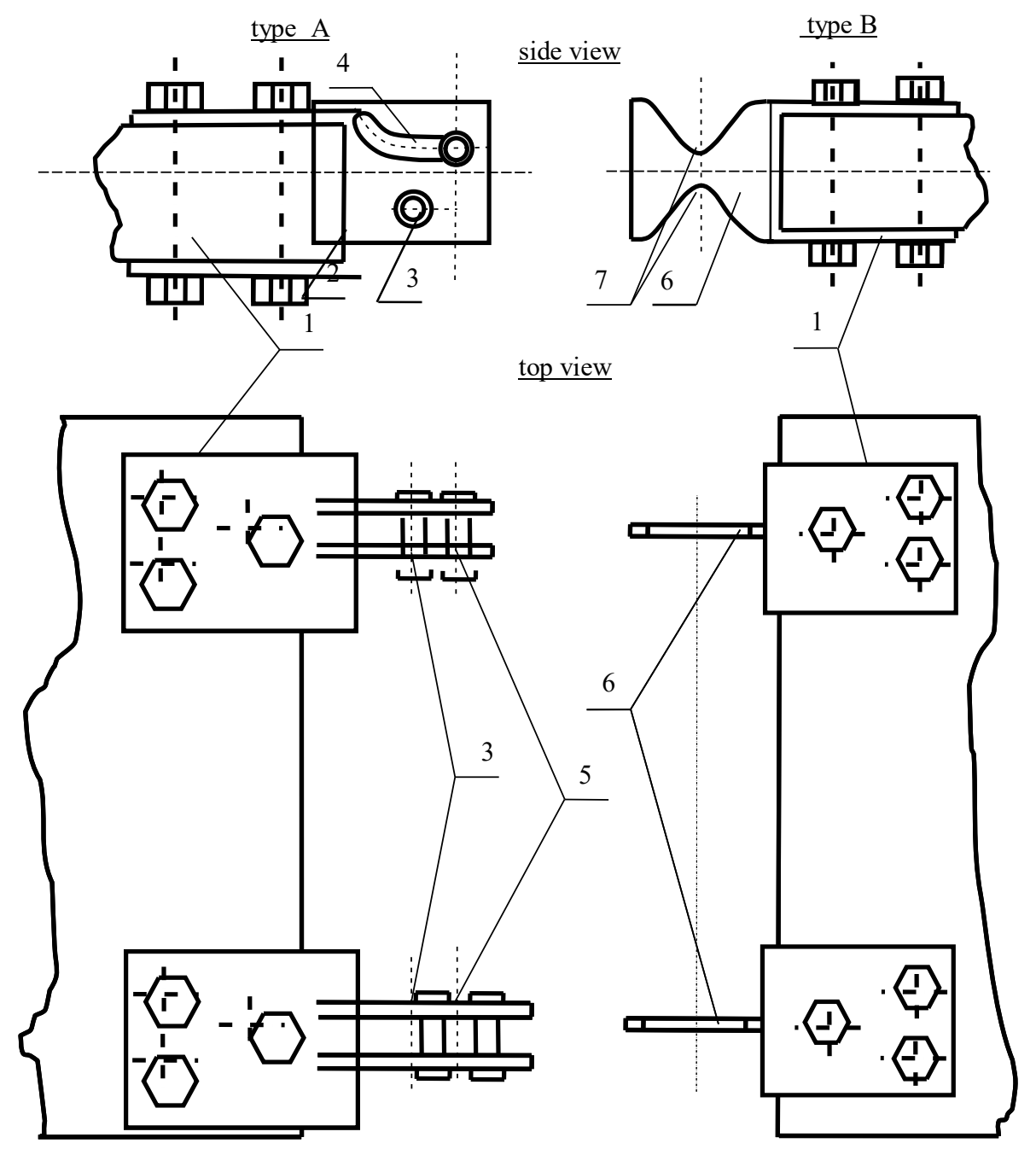

1 - bracket; 2 - fork; 3 - dowel; 4 - slot; 5 - movable pin; 6 - tenon; 7 - mortise.

Fig. 2. Design of the joint element.

Manufacture of joint devices and their fastening to the slab body should be guided by the following principles $[7,8,9,10]$ :

constructing joint devices for a plate of the required strength necessary for passing vehicles with a design single axle load of $110 \mathrm{kN}$;

minimizing consumption of materials and weight of joint devices;

compliance with technological requirements allowing for the manufacture of joint devices at the lowest cost;

simple design of joint devices, which provides a high rate of slab paving at manual installation and removal;

multipurpose design of slab joint devices, suggesting the possibility of its use not only as road pavement element, but also for the installation of temporary framed accommodation structures (e.g., for the population affected by natural disasters); 
possibility to assemble and disassemble the coating in various weather and climatic conditions, and when the joint elements are contaminated with soil;

high anti-wear characteristics of joint elements;

lack of additional components in joint elements placed outside the slab structure.

The formulated principles allow to define the main types of calculations necessary for developing the joint device structure. These include calculations of joint devices for semirigid slab connection.

Calculation of the joint device elements for semi-rigid slab connection comprises:

1) calculation of the bending moment and shear forces;

2) shearing design of dowel;

3) calculation of collapse resistance for fork and tenon (eyelets);

4) design of welds for attaching the fork and tenon (eyelets).

\section{Results}

1. Calculation of the bending moment and shear forces.

In order to calculate the joint device elements for semi-rigid (rigid) slab connection, longitudinal members are regarded as infinitely long beams (Fig. 3), and ordinates of the bending moment influence line are calculated by the formula:

$$
\mathrm{M}=\frac{\mathrm{P}_{\mathrm{K}}}{4 \alpha}
$$

where $P_{k}$ is the static pressure in the wheel (coupled wheel) tire of the design vehicle, MPa; $\alpha$ is the system flexibility coefficient.

Flexibility coefficient of the infinite beam system is determined by the following relation:

$$
\alpha=\sqrt[4]{\frac{\mathrm{C} \cdot \mathrm{B}}{4 \mathrm{EJ}}}
$$

where $c$ is the elastic base stiffness coefficient (modulus of subgrade reaction);

$\theta$ is the MRRP slab width, m;

$E$ is the slab elasticity modulus, MPa;

$J$ is the moment of inertia in the slab longitudinal section, $\mathrm{m}^{4}$.
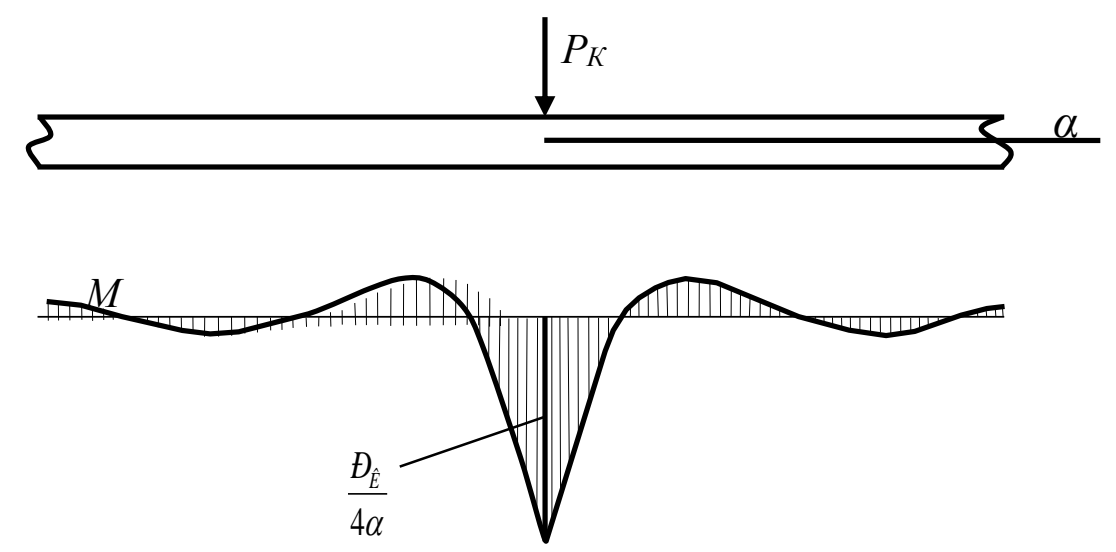

Fig. 3. The effect of concentrated force on an infinite beam and the influence of bending moment.

When performing calculations, it is necessary to select the design load that characterizes the traffic composition. As such, it is proposed to use the design load (load parameters $P=110$ $\mathrm{kN}$ ). 
Schematic diagram for determining the bending moment in the plate body that occurs from the design vehicle's coupled rear wheel, is shown in Fig. 4.

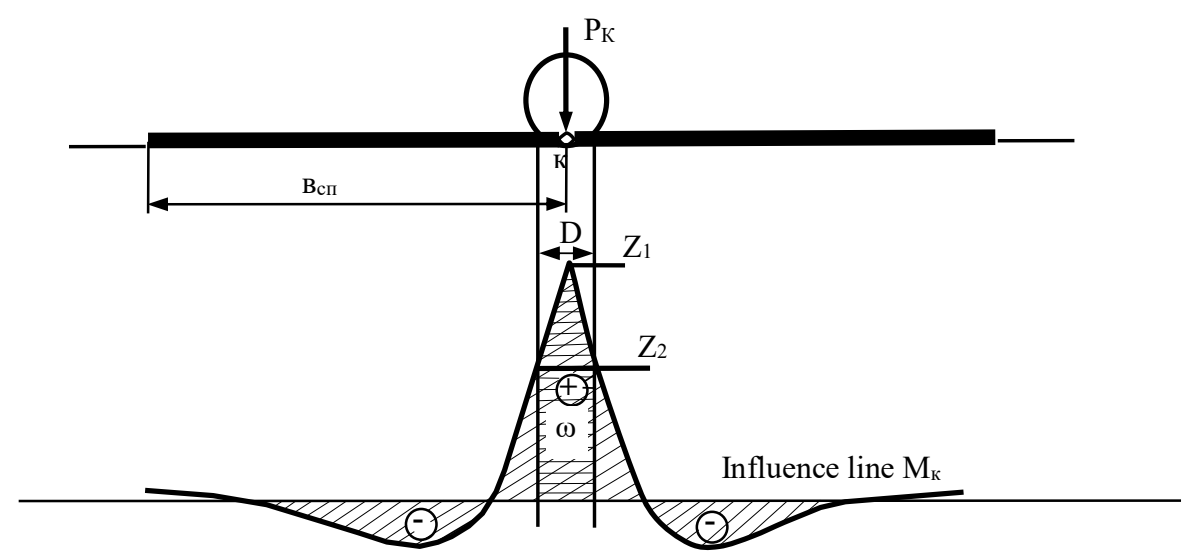

$Z_{1}$ is the influence line ordinate of the tire imprint center, $Z_{2}$ is the influence line ordinate of the tire imprint extreme edges.

Fig. 4. Influence line $M_{K}$ and the design load layout for a beam with semi-rigid (rigid) connection.

Static pressure $\mathrm{P}_{k}^{\prime}$ from the design vehicle's coupled rear wheel, considering the dynamic load factor $K_{D}=1,2$, which is usually assigned when calculating modular removable pavements, will be determined by the following relationship:

$$
\mathrm{P}_{k}^{\prime}=\mathrm{P}_{\mathrm{K}} \cdot \mathrm{K}_{D}
$$

Then the load per one wheel $\mathrm{P}_{k 1}^{\prime}$ will be determined by the formula:

$$
\mathrm{P}_{k 1}^{\prime}=\frac{\mathrm{P}_{k}^{\prime}}{2}
$$

Taking into account possible horizontal displacement of the design vehicle wheels in the coating width is calculated according to the following relation:

$$
\mathrm{y}=\frac{D}{2}+x
$$

where $D$ is the estimated tire print diameter, $\mathrm{cm}$;

$x$ is the distance from the plate edge to the tire print edge, $\mathrm{cm}$.

And possible uneven load distribution, a transverse installation coefficient $\left(K_{p y}\right)$ is introduced and determined by the relationship:

$$
\mathrm{K}_{\mathrm{py}}=\frac{2\left(\frac{\mathrm{B}}{2}+\mathrm{y}\right)}{\mathrm{B}}
$$

where $\theta$ is the MRRP slab width, $\mathrm{cm}$.

In this regard, the maximum design load $P_{\text {rasch }}$ will be calculated by the formula:

$$
\mathrm{P}_{\text {rasch }}=\mathrm{P}_{k 1}^{\prime} \cdot \mathrm{K}_{\mathrm{py}} \text {. }
$$

Load intensity, considering the contact area of the wheel with coating $D$ is determined by the relationship:

$$
q=\frac{\text { Prasch }}{D}
$$


The loaded section area of the influence line $\left(\omega_{j}\right)$ for semi-rigid (rigid) slab connection (Figure 4) is calculated by the following relationship:

$$
\omega_{j}=\frac{1}{2} D\left(Z_{1}-Z_{2}\right)+D \cdot Z_{2}
$$

The bending moment maximum value is determined by the formula:

$$
\mathrm{M}_{j}=q \cdot \omega_{j}
$$

Longitudinal bending moment $M_{j}$ per one connection joint is transmitted to the connecting elements forming a force couple with arm $t$. Then the magnitude of force $S$, which causes shear of dowels and collapse of metal, can be determined by the following formula:

$$
S=\frac{\mathrm{M}_{j}}{t}
$$

where $M_{j}$ is the longitudinal bending moment of the lock dowel for the type $A$ connecting element, $\mathrm{Nm}$;

$t$ is the arm of applying load on the lock dowel, $\mathrm{m}$.

If there is play in the joint, increased shock loads may occur. An additional overload coefficient $K_{p}=1,3$ is introduced.

Then the design force $S_{c p}$, causing shear is calculated by the following relationship:

$$
S_{\mathrm{sr}}=S \cdot K_{p}
$$

where $S$ is the force which causes shear of dowels and collapse of metal, N;

$K_{p}$ is the overload coefficient.

2. Shearing design of dowel.

When calculating the shear of dowels for hinge and semi-rigid connections, the following strength condition must be met:

$$
S_{\mathrm{sr}} \leq \frac{\pi \cdot d_{s h^{2}}}{4} n_{\mathrm{sr}} \cdot R_{\mathrm{sr}}
$$

where $S_{c p}$ is the design shearing force applied to the dowel;

$n_{s r}$ is the number of the dowel shear planes, $n_{s r}=2$;

$R_{s r}$ is the design resistance to shear (for dowels made of St.3-steel $R_{s r}=1500 \mathrm{~kg} / \mathrm{cm}^{2}$ ).

From this condition it follows that the dowel diameter $d_{s h}$ is determined by the following relation:

$$
d_{s h} \geq \sqrt{\frac{4 S_{S r}}{\pi \cdot n_{S r} R_{S r}}}
$$

3. Calculation of collapse resistance for fork and tenon (eyelets).

For a tenon (eyelet) of the type $B$ connecting element (Fig.5) the calculation is based on the condition of collapse resistance:

$$
S_{\mathrm{sm}} \leq d_{\mathrm{sh}} \cdot \delta_{1} \cdot R_{\mathrm{sm}}
$$

where $S_{s m}$ is the design collapsing force applied to the tenon (eyelet);

$\delta_{I}$ is the thickness of an average tenon, cm;

$R_{s m}$ is the design resistance to local collapse (for materials made of St.3-steel $R_{s m}=2600$ $\left.\mathrm{kg} / \mathrm{cm}^{2}\right)$. 


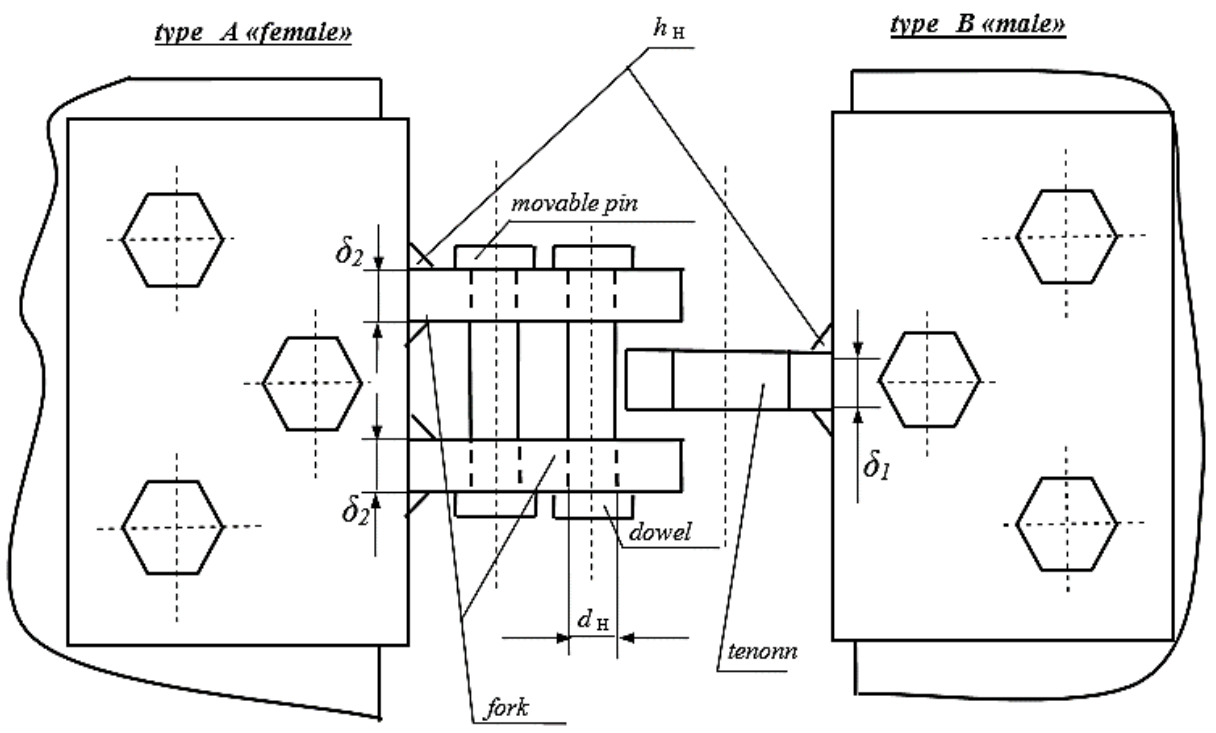

Fig. 5. Joint element design.

From this condition it follows that the $\delta_{1}$-value is determined by the following relation:

$$
\delta_{1} \geq \frac{S_{\mathrm{sm}}}{d_{s h} \cdot R_{\mathrm{sm}}} .
$$

The thickness $\delta_{2}$ of fork eyelets for the type $A$ connecting element (Fig.5) is calculated according to the following relation:

$$
\delta_{2}=\frac{\delta_{1}}{2}
$$

4. Design of welds for attaching the type A fork and type B tenon (eyelets).

When attaching the fork and tenon to the channel, which secures the joint device to the slab body, weld failure occurs from a shear along the smallest possible shear area, located in the angle bisecting plane where the seam is welded Fig.6.

Shear area $A_{s r}$ per two welded seams is determined by the formula:

$$
\mathrm{A}_{\mathrm{sr}}=2 \ell_{s h} h_{s h} \beta_{s h}
$$

where $\ell_{s h}$ is the estimated length of the weld, cm;

$h_{s h}$ is the height of the fillet weld leg, cm;

$\beta_{s h}$ is the fillet weld shape coefficient (for multiple-pass automatic and semi-automatic welding $\beta_{\text {sh }}=0,7$ ). 


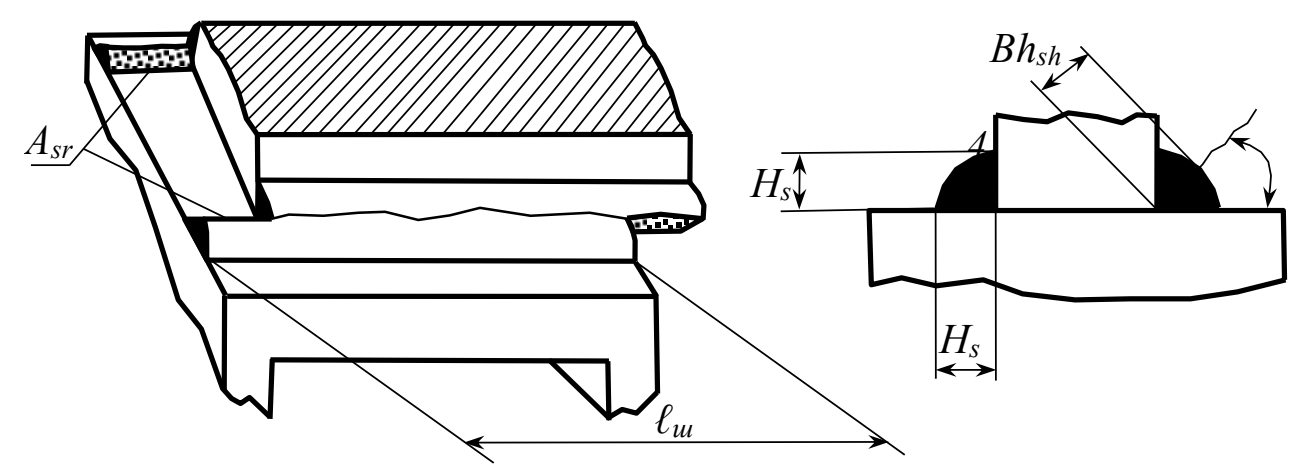

Fig. 6. Joint fillet welds working in shear.

In a uniform distribution of shear stresses over the weld shear area, the calculation is based on the strength condition:

$$
\frac{S_{\mathrm{sr}}}{A_{\mathrm{sr}}}=\frac{S_{\mathrm{sr}}}{2 \ell_{s h} \beta_{s h} h_{s h}} \leq R_{\mathrm{sr}}
$$

where $R_{s r}$ - is the design shear resistance of the fillet weld material, $R_{S r}=1100 \mathrm{~kg} / \mathrm{m}^{2}$ )

Then the $h_{s h}$-value can be determined by the formula:

$$
h_{s h}=\frac{S_{\mathrm{sr}}}{2 \ell_{s h} \beta_{s h} R_{s h}} .
$$

\section{Conclusions}

Thus, the proposed design of joint device allows for the high technological effectiveness of manual installation and removal of road pavement slabs from composite materials. Multipurpose design of slab joint devices suggests their possible use not only as road pavement elements, but also for the installation of framed structures of various types.

\section{References}

1. I.G. Sobko, S.T. Yalonen, Yu.G. Lazarev, S.V. Alekseev, Construction of removable road pavement on a reinforced base. Utility Model Patent RU 27600 U1, 10.02.2003, Application No. 2001134382/20 (2001)

2. G. Sobko, S.T. Yalonen, Yu.G. Lazarev, S.V. Alekseev, Design of modular removable road pavement on a reinforced base. Ru RU 27600 U1, 10.02.2003. Application No. 2001134382/20 (2001)

3. S.A. Ukolov, Paving slab made of polymer materials. Patents and Trademarks. Utility Model Patent No. 90079 (Federal Service for Intellectual Property, Moscow, 2009)

4. Y. Lazarev, C. Medres, J. Raty, A. Bondarenko, Transportation Research Procedia 20, 396-400 (2017)

5. B.N. Karpov, E.A. Alekseeva, Bulletin of Civil Engineers 2(55), 192-5 (2016)

6. G. Sobko, S.T. Yalonen, Yu.G. Lazarev, S.V. Alekseev, Design of modular removable road pavement on a reinforced base. Utility Model Patent RU 27600 U1, 10.02.2003. Application No. 2001134382/20 (2001) 
7. N.A. Ermoshin, D.S. Bukatov, Transport of Russia: problems and prospects, Materials of the international research to practice conference, 211-214 (2018)

8. N.A. Ermoshin, IOP Conference Series: Materials Science and Engineering 753, 3 (2020)

9. D.A. Filippov, S.A. Ukolov, National Priorities of Russia. Series 1: Science and Military Security 1(8), 106-110 (2017)

10. I.A. Zolotar, Economic and mathematical methods in road construction (Transport, Moscow, 1974) 